\title{
Beyond Medications: Understanding Executive Function Deficits of Children with ADHD Through Jungian Sandplay Therapy*
}

\author{
Byungho Jung**
}

\begin{abstract}
$<$ Abstract $>$
This study aims to search for effective therapeutic approach for children with ADHD by understanding their symptoms as well as their difficulties. This researcher will review the relationships between executive function deficits of Children with ADHD and their symptoms of inattention and hyperactivity-impulsivity. Then, the effectiveness and limitations of psycho-stimulants, the major intervention for children with ADHD, will be reviewed. To understand executive function deficits of Children with ADHD in analytical perspective, this research will review Jung's archetypal psychology, the theories of Erich Neumann as well as Erick Edinger, and Jungian sandplay therapy. Finally this researcher will analysis a clinical case of child with ADHD based on Jungian sandplay therapy. The result is that the sandplay therapy provided for child with ADHD a safe place to explore his difficulty and assisted him to meet the Self who would revitalize his fragile self so that he could reduce symptoms of ADHD and increase social skills.
\end{abstract}

Keywords : Jungian sandplay therapy, ADHD, executive function, ego conscious development

\footnotetext{
* This article is funded by Healing \& Counseling Graduate University and analyzes the recent research trend of executive function deficit as well as a clinical case partially based on the author's doctoral dissertation (Healing Children with Attention Deficit Hyperactive Disorder Through Sand play).

** Byungho Jung, Professor, Department of Family Counseling, Healing \& Counseling Graduate University (play-therapy@hcg.ac.kr)
} 
Journal of Symbols \& Sandplay Therapy, Vol.10 No.1.

\section{I . Introduction}

In clinical practice, childhood behavioral problems that were categorized as disorders of attention, impulsivity, and hyperactivity have presented a challenge for practitioners. These symptoms, referred to as Attention Deficit Hyperactivity Disorder, have become one of the most prevalent neuropsychiatric disorder of childhood(Caspersen at el, 2017). To define the primary characteristic as well as symptomatology of children with ADHD, a enormous amount of research has been published(Barkely, 2013).

One of major interventions for those children with ADHD is medication(Stolberg, 2017), which help them adjust to the class by increasing attention span(Ibrahim at al, 2016). However, it has limitations(Meppelink at al, 2016) to assist them to improve their ability to resolve their difficulties in social and academic fields. Professionals can assists those children when what makes them be disruptive is understood and then this most needy group of children can be transformed from chaos to order. People often think that those children have disruptive behaviors due to executive function deficits in general. The executive function mentions to multiple, interrelated higher order cognitive process in controlling for purposeful, goal-directed behavior (Kingdon at el, 2016). But in Jungian perspective, children with ADHD have those difficulties because their fragile ego conscious do not fully develop yet; executive function deficits are understood as the result of their undeveloped ego conscious. Jungian sandplay therapy based on Jung's archetypal theory explains how fragile ego conscious would develop as it comes cross archetype in the sand box. Archetype is fundamental life resource as well as symbolic expression of God, which can help the shaky ego conscious of children with ADHD develop their pass way to be mature, that is to say individuation process. Their impulsive and disruptive behaviors need to be understood in terms of this archetypal psychology, which truly leads us to know the dynamics of the behaviors of these children and to find effective way to help them. In therapeutic setting, We can witness the evolution of ego consciousness of these children in the sand box where they can come across the Self, one of main archetypes. Then they are able to be aware what is going on in their lives rather than impulsively responding to others. 


\section{П. ADHD}

Current DSM 5(APA, 2013) describes the essential feature of ADHD as a persistent pattern of inattention and hyperactivity-impulsivity. The prevalence of ADHD is estimated to affect up to $7 \%$ of children(Fried at al, 2016). Symptoms of children with ADHD lead to significant social, academic and health problems with lifelong negative effects(Bolat at al, 2016). Those children often have experience difficulties in social interaction with peers and social isolation (Alizadeh at al, 2016). Youths exhibiting disruptive behavior tend to have a higher high school dropout rate, below-average achievement test scores, lower grade point averages, and greater incidence of underachievement(Johnson, at al, 2005). Symptoms of Gender differences in ADHD have been found. Girls are less impulsive and exhibit fewer conduct problems in the classroom (Lumley at al, 2002) while Boys with ADHD demonstrate disruptive behaviors more frequently and display higher ratings of aggression (Maniadaki, at al, 2005).

The range of clinical impairment in ADHD suggests the core deficits such as impairments of executive function, shortened reward gradients and deviating motivational style, poor state regulation, and deficits in temporal processing(Caspersen at el, 2017). Reviewing executive function deficits is one of the ways to understand the clinical descriptions of the core nature of ADHD.

\section{Executive function deficits of Children with ADHD}

Although the diagnosis of ADHD is based on behavioral observation, cognitive deficit can be detected in the domain of executive function(Mary at al, 2016). Executive function means the self-directed action of an individual to self regulate. It is actions we perform to ourselves and direct at ourselves in order to accomplish self control, goal-directed behavior and the maximization of future outcomes(Barkely, 1997). Executive function includes such abilities as components of attention, reasoning, planning, inhibition, interference control, and working memory(Biederman at al, 2004). In 2002 an international consensus statement signed by 86 of the leading international scientists in the field of ADHD research states that ADHD relates to 
Journal of Symbols \& Sandplay Therapy, Vol.10 No.1.

a serious deficiency in a set of psychological abilities linked to several specific brain regions (Houghton, 2006).

The impairments of the executive function mean that people cannot generate or utilize a plan that incorporates multiple tasks and temporal consideration, and also they are not able to inhibit immediately gratifying behaviors for the sake of long range goals(Gilmore, 2002). Researchers have a high connection between Executive function and daily activities such as social skills and academic functioning(Kingdon at al, 2016). Barkely(2003) implies that children with ADHD have impaired frontal lobe structures through the executive functions. ADHD has been described as a disorder that mainly rarifies response inhibition. Consequently, children with this problem typically reveal deficits in a broad range of tasks in terms of assessing executive functions (Barkley, 1997). Due to executive function deficits, children with ADHD cannot generate or utilize a plan that incorporates multiple tasks and temporal consideration, and also they are not able to inhibit immediately gratifying behaviors for the sake of long range goals(Gilmore, 2002).

\section{Medication intervention}

Ritalin has been the psychostimulant medication most often prescribed for treatment of ADHD(Doherty et al, 2000). Psychostimulates are believed to increase central dopamine concentration by occupying and blocking the dopamine transporters, which reduce motor activity and impulsivity and which increase sustained attention(Greenhill, 2005). Behavioral inhibition of children with ADHD is seen to be directly affected by stimulants, allowing children to sit more easily, pay attention, and get alone with other children and their parents. Their neuropsychological performance is likely to be enhanced if they take psychostimulants (Epstein et al, 2006). Psychostimulants also improve the performance of children with ADHD in increasing retention and recall(Paule et al, 2002).

Psychostimulants is a powerful option in helping children with ADHD, but there are also concerns regarding its use as a primary intervention. Even before ADHD was fully classified as a disorder, serious concerns have been raised about using psychostimulants for children(Stolberg, 2017). Although the research on stimulant medications reveals their effective 
in certain situation, they were not as effective in other situation such as helping them on tests or on home work after school. It is less sure if they would help children with ADHD in terms of academic improvement(Doherty at el, 2000).

These stimulants also have only short-term effects, treatment adherence is often low and most importantly medications has serious side effects(Meppelink at al, 2016). Common side effects include insomnia, decreased appetite, weight loss, headache, stomachache and small increase in hart rate and blood pressure(Barkley, 2013).

\section{Precedent research}

In Korean, a meta-analytic review of non-pharmacological interventions for children with ADHD between 2000 and 2015 reported that significant effects were observed in ognitive-behavioral and art therapy interventions that were signed to improve their academic achievements(Kim, An, \& Koo, 2016). Another study found that the typical intervention setting for children with ADHD was a counseling center where provided them for group counseling, play therapy, sandplay therapy, and theraplay, which were effective for improving their attention and self-control(Choi, 2012).

The research of meta-analysis on the effect of group play therapy on children with ADHD from 2000 to 2015 reported that it was effective for children with ADHD(Lee \& Kim, 2017). There were other researches to search for interventions to help them improve their positive behavior. The parent-child interaction play therapy program for children with ADHD assisted their parents to develop parenting skills. As a result, children were able to increase attention span, cooperative behavior, positive interest in others, and scrupulosity(Hong \& Kim, 2013). Integrative play therapy helped children with ADHD decrease hyperactivity, impulsiveness, and their problematic behavior(Lee, 2004). The music therapy which was attracted to children with ADHD treated their maladjusted behaviors through the musical activities(Rhee, 2015) and increased concentration, social skills, cooperative behavior, and self control(Kim, 2008). The art therapy also showed in a positive change on the attention test of the children with $\operatorname{ADHD}(\operatorname{Im}$, Lee, \& Song, 2015). Some researchers studied a potential therapeutic intervention in meditation for them although there was not much research. Then, 
Journal of Symbols \& Sandplay Therapy, Vol.10 No.1.

they insisted that there were sufficient data which was possibly leading the development of medication therapy for them(Yoon, 2010).

Sandplay therapists had also done research for children with ADHD and found that Sandplay helped them express deepest inner conflicts and the problems by making safety frame, was the effective method to decrease their anxiety and was effective in increasing the level of social adjustment(Esmaelili \& Soltanizadeh, 2015). The research of exploring positive changes in children with ADHD who participated in sandplay reported that they showed the positive changes on attitudes, a daily life, and interpersonal relation(Byeon, Eun-Jin1 - Park, Byung, 2018). Although it was the research of university students with ADHD, who were experiencing pressures and conflicts in university life, the study found that after receiving sand play therapy, they significantly decreased in anxiety, interpersonal stress, and salivary cortisol(No \& Kim, 2013).

Many studies have been conducted to help children with ADHD, but those studies do not theocratically address how children have decreased negative behaviors and increased positive behaviors. Although sandplay studies have also shown that those children are able to reduces their symptoms and problematic behavior while increasing positive behavior, those studies do not explain the therapeutic process relating to their executive function deficits. This study will discuss children with ADHD in terms of lack of executive function and how the function deficit is related to the fragile ego in Jungian psychology. It will also search for a long term therapeutic intervention for children with ADHD rather than simply introducing medication option for them to reduce their symptoms.

\section{Conversation between psychoanalyst and executive function}

Psychoanalyst have discounted the diagnosis of ADHD because it is purely descriptive and behavioral. But it can possibly be understood in psychoanalytic terms as a disturbance in ego function of $\mathrm{ADHD}$, which indicates a disturbance in fundamental ego capacities. The leading neuroscientists explain ADHD through the notion of executive function that can be correlated with the ego-psychological dimension(Gilmore, 2002). The clinical presentation of children with ADHD is related to characteristic of the executive function deficits(Conway, 
2012).

In Jungian perspective, the executive function deficit could be understood as the problems of fragile ego that has not been developed yet because it has not had a change to meet archetypes. Jungian sandplay, based on Jung's Archetypal psychology, throughly explains how the fragile ego conscious would develop as it comes cross archetypes in the sand box.

Behavioral and pharmacological treatments are often useful in controlling symptoms in short term range, but they are less effective helping people move to the point at which the symptoms of $\mathrm{ADHD}$ are permanently relieved, nor do they help achieve a more coherent sense of self (Jones, 2002). Jungian sand play therapy is searching for long term effectiveness instead of focusing on a short term change. The clients feel the sense of sand and have the ability to solve problems themselves by expressing thoughts and feelings in unconsciousness(Jang, 2010). It aims the connection between wounded ego conscious and archetypes in as seen a sand tray. If the connection happens, delayed ego conscious developmental process would be activated and the ego consciousness of children with ADHD would be healed.

\section{Jungian Sandplay Therapy}

Jungian sandplay therapy is one of the play therapy models and allows us to understand and describe cleint's psyche(Thapa \& Jang, 2016). It emphasizes the importance of the positive therapeutic alliance in activating the self-healing archetype embedded in the child's psyche(Allan \& Brown, 1993). Sand play can be an effective way to help children with ADHD in the way of reconnecting their disturbed ego conscious with archetypes, the fundamental life resource according to Jungian theory.

\section{Jungian Sandplay Therapy}

As we understand that children with ADHD have executive function deficits due to undeveloped ego conscious the ego, sandplay is one of the appropriate therapeutic intervention for them because it amis to develop fragile ego by encountering the Self symbolically. In 
Journal of Symbols \& Sandplay Therapy, Vol.10 No.1.

clinical practices, Kalff(2003), a founder of Jungian sandplay, observed the ego conscious developmental process that Erick Neumann theoretically described through mythological methods in sand play therapy. She explained three stages of ego consciousness development process from archetypes based on Neumann's theory in sand play therapy. These were animal-vegetative, fighting, and adaptation to the collective. They do not have to be in order, but usually the adaptation to the collective comes in the end.(Bradway \& McCoard, 1997).

A basic concept of sand play therapy is that given the proper conditions in the deep unconscious level, an autonomous tendency for the psyche to heal itself would emerge(Weinrib, 2004). Therapists need to provide a proper environment for children with ADHD, and then they would naturally experience the psyche that helps their ego conscious. The underlying assumption of sand play therapy is that the psyche will lead the individual to wholeness while projecting their unconscious into the sandbox. The sand play assumes if the unconscious is given proper conditions, there is an autonomous tendency for the psyche to heal itself(Weinrib, 2004). Then, the unconsciousness comes up while the healing proceeds. By the permissiveness and acceptance of inner child work, sand play brings unconscious material to consciousness and honors healing of the ego conscious that is lost between the real world and the unconscious world(Amatruda \& Simpson, 1997).

A main goal of sand play therapy is to relate the ego to the self, so the ego gives up the illusion of dominance, which results in reestablishing a connection between consciousness and unconsciousness. All children who received the Jungian sand play therapy brought archetypes into the sand tray without any intentions of making them, which opened doors that gave another change preceding their ego conscious developmental process. Then their ego conscious stagnated and wounds were regenerated, which meant that they were free from their symptoms caused by the conflicts between the internal psyche and outside world. These archetypes have been engraved by endless repetition into our psyche constitution(Enns, 1994) and they are ready to help our ego conscious. Then the ego conscious was revitalized by the experience and connected with the Self. The ego conscious developmental process was symbolically described in a sand box through the use of miniature toys.(Kalff, 2003).

Children with ADHD experience the impairments of the executive function so they 
struggle to generate a plan that incorporates multiple tasks and temporal consideration. The goal of sand play is to help children with $\mathrm{ADHD}$ to reconnect their disturbed ego conscious with archetypes. Sand play is a place where children with ADHD are able to experience the constellation of archetypes that leads to the emergence of the renewed ego. It provides for clients to get into the preverbal, matriarchal areas of the psyche so they are able to connect with unconscious materials that are valuable in reconstructing psyche structures(Bradway \& McCoard, 1997).

\section{Case study 1 )}

Choi was a seven years old boy, who have severe behavioral problems at school such as punching his peers, not following rules, and moving around the class without permission from his teacher.

He was diagnosed with ADHD due to above symptoms(R/O Autism). His mother said that when Choi was upset, he could not control his behavior; he also had poor social skills so he was not able to get along with peers and continued to experience rejection from them. According her, he did not follow her direction since he was three years old. His mother said that he had difficulty to speak until he was three, but after receiving language therapy, he did not have any problem in speaking Korean. She described him as a difficult child since he was very young.

In the first session, this researcher invited him into the play room; Choi was a bit shy and polite and did not display aggressive behavior. When he was told only rule in this room is to do what he want, he smiled and started to play in the sand box. He built a city by placing houses, plants and cars. Later he brought a big ship and played with it for a while; then he placed a police car as well as a fire truck and however, soon destroyed the whole city. Weinribs (2004) explains that the sand tray is protected and free space and says that unredeemed demonic energies can be transformed by allowing the expression of repressed, aggressive need $\mathrm{He}$ seemed to express all his destructive aggressions by destroying the city that

1) The client's parent allowed the researcher to write the child case in this paper. This case lasted about six months in 2017 in Korea. 
Journal of Symbols \& Sandplay Therapy, Vol.10 No.1.

he carefully built in order to transform them. In general, the fighting stage exhibits struggles that the ego conscious faces between inner and outer forces. However his fighting stage was very intensive so his ego consciousness had enormous difficulty to deal with the conflict.

Choi continued to display his ruthless aggression toward this therapist through the sand box as well as play about 3 months; However, he never harm this therapist physically, but he only expressed his aggression through play. Sometimes he said that he killed this therapist by firing a mini lager gun and then he pretended to heal the therapist as a doctor. Other times he said that he burned $90 \%$ of this therapist's body by flame; he then said that he helped the therapist recover from the burn. His most favorite play was 'prison play.' $\mathrm{He}$ said that he was a prison guard while this therapist was a prisoner. He ordered this therapist to escape from the play room and but as soon as the therapist got out of it, he placed the therapist in it again. However, his aggression gradually decreased and intensity of his anxious feeling became moderated.

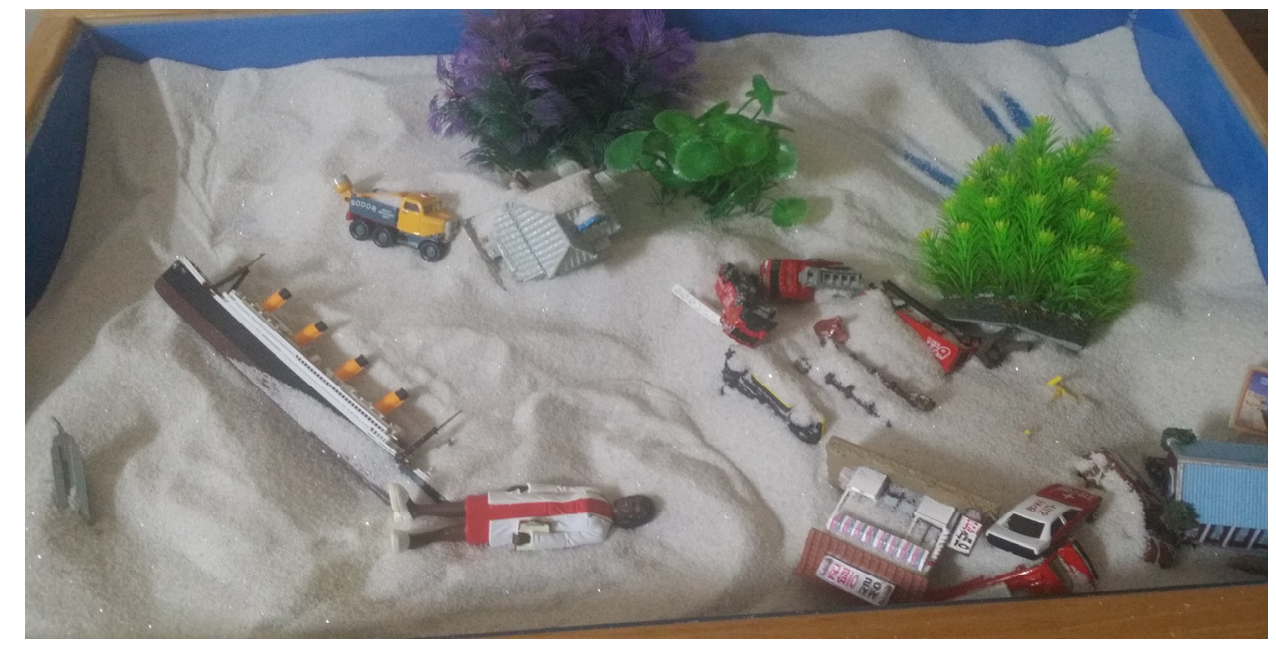

Figure 1. A Destroyed City

In the fifth session, when he saw the sand box, he came into it and sprinkled sand to himself, He then placed a excavator in the box and also sprinkled sand to it. He then took a human figure and buried in the middle of the sand box as saying "he was dead." He then put a rocket at the top of the tomb, but soon he took it out of the box and made a rode at 
the right side of the tomb. After saying "five years later," he displayed houses, cars, and plants at the upper side of sand box. Finally he placed a big house at the top of the tomb, and put a huge rock as well as windmill behind of it. Weinribs(2004) explains that death indicates rapid penetration into deeper levels of personality that possibly have a chaotic quality while entering patients' own underworld and reached untapped raw energy so that they begins to see varying degree of resolution of problems In this session, he seemed to experience his death and to start resolve his personal issues relating to his father who treated him roughly.

In the ten session he made a huge circle and placed cars there. He then said that people moved in this town, put them on the circle, build houses on the right side of the box. He also made an inside circle where people and cars were moving, put houses in the middle of the circle, and placed fens as if he wanted to protect the inside circle from the outside. He put a public telephone in a small gab between fens on the upper left side of the inner circle and a bridge on the right side of it. Finally he placed a medieval man who appeared to cross over the bridge toward outside. Kalff(2003) says that the manifestation of the Self, emerging the image of psychic wholeness as circle, is the most important moment in developing weak ego consciousness so that she aims to give the child's Self the potentiality of constellations and manifesting in therapeutic process. This picture revealed that Choi encountered archetypes. Outside circle may indicated the Self-constellation and under the protection of the Self, his

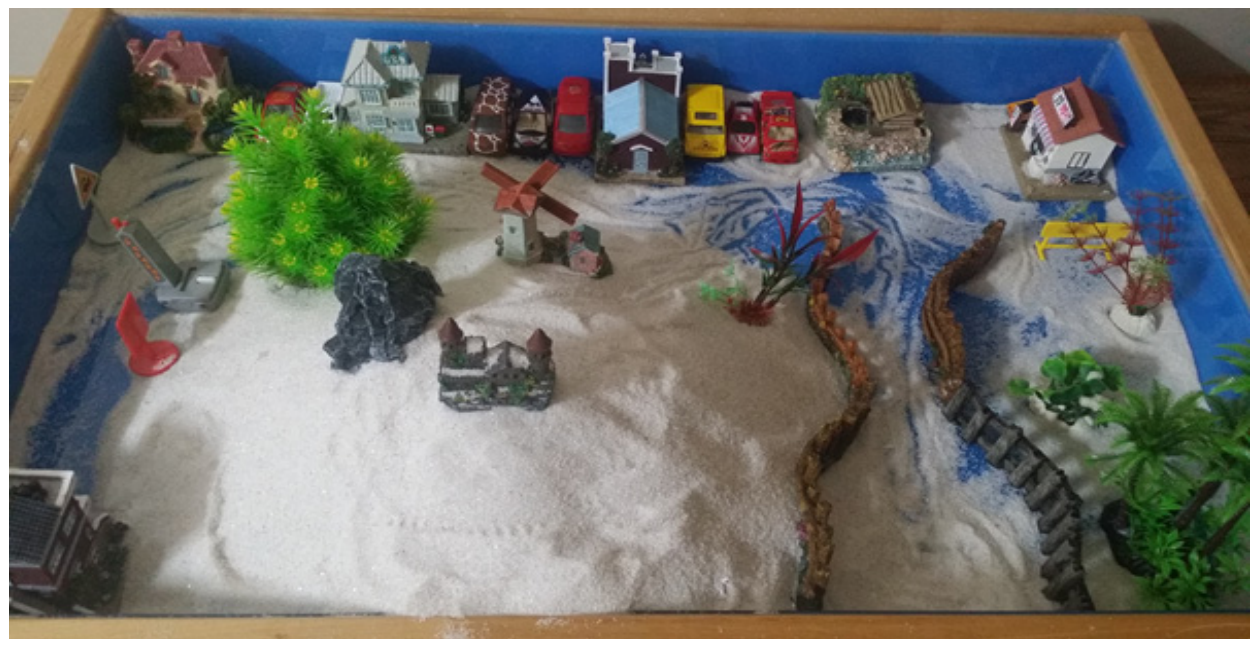

Figure 2. Death and Resolving problems 
Journal of Symbols \& Sandplay Therapy, Vol.10 No.1.

fragile ego was able to develop a strong new sense of himself by symbolically expressing people who just moved in the town. Weinribs(2004) states that transposing inner content into concrete outside world in turn, becomes a bridge to the world. In the picture, the bridge could be a strong evidence of connection between the outside world and the inner content. The medieval man who crossed over the bridge might symbolically represented his ego that went toward outside world after encountering the Self. People and cars in the outside and the inside circle moved from right to left, which was psychologically analogous to a direction toward consciousness(Kalff, 2003). As libido energy under the Self constellation moved toward the outside, the medieval man, a symbolic representation of the new ego also move toward there. This picture may symbolize a centering process, representing the powerful transformation. of ego. Since this session, his behavioral problems became less severe and reduced frequency of disruptive behavior. After three months later, he was able to control over his destructive pattern in interacting with peers. His mother reported that Choi intented to slap his friend at school, but right before hitting him, he changed his mind and gently touched his peer's cheek. As Weinribs(2004) says, expanded ego-consciousness may help him make a better choice to response to others. In addition to this therapeutic intervention, his parents put a lot of effort to assist Choi to improve his ability to control over his impulsivity. Their persistent support for

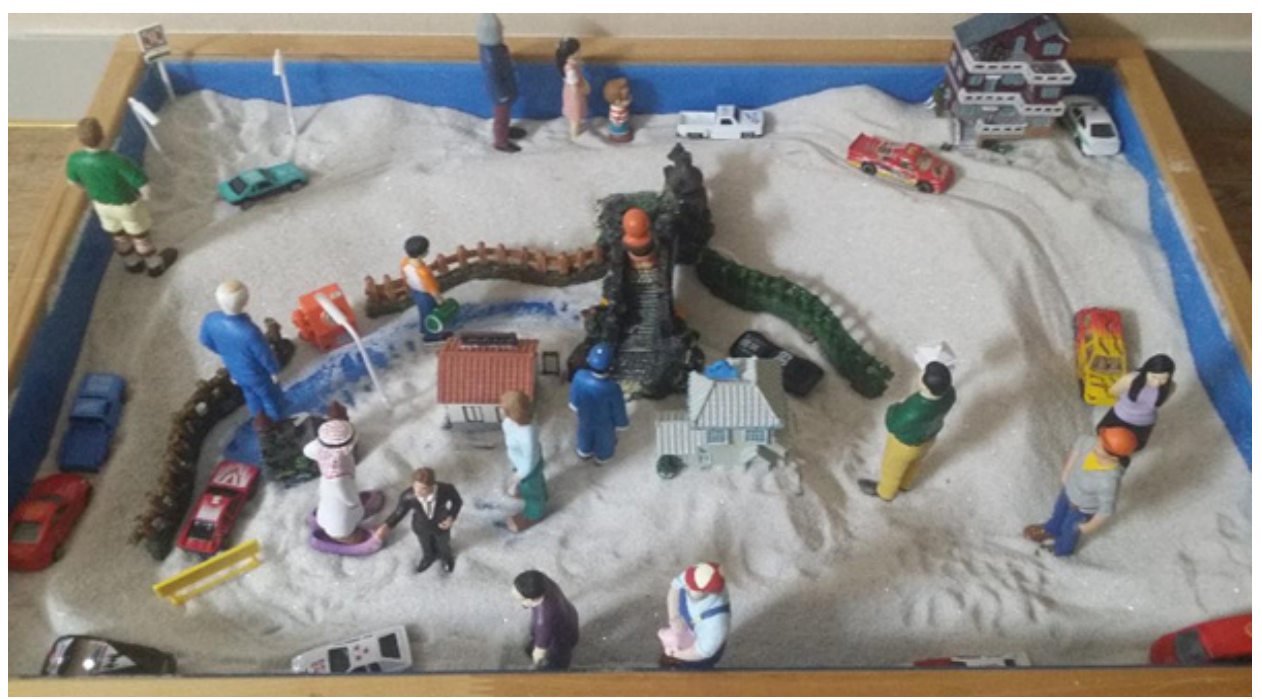

Figure 3. the Self-Constellation 
him is one of the major contributing factor of changing his behavior.

\section{Discussion and Conclusion}

Theoretically understanding the development process of the ego conscious in Jungian perspective is important to help children with ADHD. Through a full connection with their archetypes, their disturbed ego is able to touch the spring and resource of life. Jung broadly described the concept of archetype to us, and his followers such as Edward Edinger and Erich Neumann deeply explained the relationship between ego and collective unconscious.

Neumann(1954) provides therapists a theocratical explanation of how the ego conscious evolves from the unconscious, the uroborous through mythological stages, which allowed the ego conscious to be transformed and to be consistently experiencing a new relation to the archetypes. In the beginning, there are no differences between the ego conscious, but in the next, the ego conscious starts to reflect upon the uroborous while detaching from the uroborous. Finally, a conscious system is established and can stand by itself apart from the unconscious. According to Edinger(1972), the ego is the center of the conscious personality just as the self is the regulating and unifying center of the total psyche. In the first stage, there are nothing exists but the self-Mandala and then, emerging ego is beginning to separate from the self. Finally, an ideal theoretical limit which probably does not exist in actuality occurs, as it represents a complete consciousness of the ego-self axis and a total separation of ego and self. The ego conscious gradually comes out of the self, archetype and achieves its autonomy while keeping a connection with the self through the ego-self axis. Neumann and Edinger well illuminate the separation process of the ego from the self.

Cho initially expressed redeemed demonic energies that can be transformed by allowing the expression of repressed, aggressive need In the sand play, he then experienced death that indicates rapid penetration into deeper levels of personality and reached untapped raw energy so that he began to see varying degree of resolution of problems. Finally he encountered the Self in the sand tray so his fragile self was able to regenerate by symbolically crossing over the brige toward the world. Then he could interact with his peer in an appropriate manner. 
Journal of Symbols \& Sandplay Therapy, Vol.10 No.1.

The goal of this study is to look for an alternative intervention while overcoming the limitations of current therapeutic models for children with ADHD and explain how they can be healed theoretically and clinically. There is no doubt that psycho-stimulants are fast and effective, but the conventional treatment models based on psycho-stimulants minimize complex issues with which children with ADHD struggle. The current model ignores physical emotional traumas that they possibly have suffered, so they are re-traumatized. Pharmacological treatments are useful in controlling their symptoms, but they do not help them move to the point that eventually the symptoms of ADHD are permanently relieved(Jones, 2002).

Another goal of this research is to understand Children with ADHD, who have difficulties to execute daily activities due to their impaired executive function. In Jungian perspective, the executive function deficits of children with ADHD could be understood as the problems of fragile ego. They experience problems producing or developing a plan and inhibiting instantly gratifying behaviors. Jungian therapists believe that their ego conscious is disturbed and should be healed in terms of being reunited with the archetypes. The Jungian sandplay therapy focuses on the ego conscious developmental process and could help the disturbed ego conscious of children with ADHD to regain its strength while being connected with archetypes, the deep healing psyches, in the sand tray. The Jungian sand play therapy facilitates healing as well as transformation in young children(Green \& Gibbs, 2010) and offers the possibility that the disturbed ego conscious of children with ADHD would experience the transformation of being secure, expanding its limitation.

The conclusion from this study is that Jungian sand play therapy could be an alternative intervention for children with ADHD. The goal of Jungian sand play therapy is to relate the ego to archetypes. Sandplay therapy can promote healing tendency by ensuring autonomous dynamics(Kwak \& Seo, 2018) and clients project their impaired ego conscious onto the sand tray. By experiencing archetypes, the fundamental life resources, they have the chance to regenerate their ego conscious.

This study has limitations in providing sufficient data to prove. However, in the future, a more extensive study will be undertaken to understand children with ADHD symptoms and find that their problems cannot be healed by simple miraculous medications, but 
through deep understanding of the psyche as well as sincere care.

\section{References}

Alizadeh, H., Walton, X. F., \& Soheili, F. (2016). Social interest in children with and without attention-deficit/hyperactivity disorder. The Journal of Individual Psychology, 72(4), 290-307.

Allan, J. \& Brown, K. (1993). Jungian play therapy in elementary schools, guidance \& counseling, Special issue: Counseling and children's play, 28(1), 30-41.

Amatruda, K. \& Simpson, H. P. (1997). Sandplay: sacred healing - a guide to symbolic process. Printed in the United States of America

Barkely, R. A. (1995). Taking charge of ADHD: The complete, authoritative guide for parents. New York: The Guilford Press.

Barkey, R. A. (1997). ADHD and the nature of self-control. New York: The Guilford Press.

Barkely, R. A. \& Mash, E. J. (2003). Child psychopathology. New York: The Guilford Press.

Barkey, R. A. (2013). Attention-deficit hyperactivity disorder; a bandbook for diagnosis and treatment. New York: Guilford Press.

Bolat U. G., Ercan, S. E., Salum, A. G., Bilac, O., Massuti, R., Ozalsan, U. T., Bolat, H., \& Rohde, A. L. (2016). Validity of proposed DSM-5 ADHD impulsivity symptoms in children. European Child Adolescent Psychiatry, 25, 1121-1132.

Bradway, K. \& McCoard, B. (1997). Sandplay: silent workshop of the psyche. London: Routledge.

Byeon, E. J. \& Park B. D. (2018). Exploring positive changes in children with ADHD tendencies participating in sand play activities. The Journal of Special Children Education 20(2), $117 \sim 145$

Caspersen, I. D., Petersen, A., \& Plessen, K. J. (2017). Perceptual and response-dependent profiles of attention in children With ADHD. Neuropsychology, 31(4), 349-360.

Chelonis, J. J., Edwards, M. C., Schulz, E. G., Baldwin, R., Blake, D. J., Wenger, A., \& Paule, M. G. (2002). Stimulant medication improves recognition memory in children diagnosed with attention-deficit hyperactivity disorder. Experimental and Clinical 
Journal of Symbols \& Sandplay Therapy, Vol.10 No.1.

Psychopharmacology, 10(4). 400-407

Choi, J. A. (2012). Literature review of play therapy intervention for children with ADHD, Journal of the Korean Home Economics Association, 50(5), 125-138

Conway, F. (2012). Psychodynamics psychotherapy of ADHD: a review of the literature. psychotherapy, 49(3), 404-407.

Doherty, S. L., Frankenberger, W., Fuhere, R., \& Snider, V. (2000). Children's self-reported effect of stimulant medication. International Journal of disability, Development and Education, 47(1), 39-54.

Edinger, E. F. (1972). Ego \& archetype. Massachusetts: Shambhala Publication.

Enns, C. Z. (1994). Archetypes and gender: goddesses, warriors, and psychological health. Journal of Counseling \& Development, 73, 127-133.

Epstein, J. N. (2006). Assessing medication effects in the MTA study using neuropsychological outcomes. Journal of Child Psychology and Psychiatry, 47(5), 446-456.

Fried, R., Chan, J., Feinherg, L., Pope, A., Woodworth, K. Y., Faraone, V. S., \& Biederman, J. (2016), Clinical correlates of working memory deficits in youth with and without ADHD: a controlled study. Journal of Clinical and Experimental Neuropsychology, 38(5), $487-496$.

Esmaeili1, A \& Soltanizadeh, M. (2015), The effects of sand therapy on the anxiety, positive \& negative emotions \& social adjustment pr-school children with attention deficit hyperactivity. Journal of Chemical and Pharmaceutical Research, 7(10), 972-977.

Gilmore, K. (2002). Diagnosis, dynamics, and development: considerations in the psychoanalytic assessment of children with ADHD. Psychoanalytic Inquiry, 22, 372-390.

Green, J. E \& Gibbs K. (2010). Jungian sandplay therapy for preschooler with disruptive behavior problems. American Psychological Association.

Greenhill, L. L. (2005). The science of stimulant abuse. Psychiatric Annals, 35(3), 210-214.

Goldstein, M., \& Goldstein, S. (1998). Managing attention deficit byperactivity disorder in children. New York: John Wiley \& Sons, Inc.

Hillman, J. (2004). Archetypal psychology. Connecticut: Spring Publications.

Hong, J. Y. \& Kim, H. H. (2013). A case study of parent-child interaction play therapy 
program for the ADHD children, The Journal of Play Therapy, 17(2), 73-91.

Ibrahim, K., Vogt, C. \& Donyai, P. (2016). Caught in the eye of the storm: a qualitative study of views and experiences of planned drug holidays from methylphenidate in child and adolescent ADHD treatment, Child and Adolescent Mental Health, 21(4), 192-200.

Im, Y., Lee, K., \& Song, J. (2015). Effects of Art therapy using natural material on attention-concentration improvement of Children with ADHD, The Journal of Special Children Education, $17(2), 257 \sim 284$.

Jang, Nan-Yi. (2010). The effect of sandplay therapy on ADHD university students with self-esteem \& personal relationship problem. Symbols \& Sandplay Therapy, 1(1), 61-81.

Johnson, W., Mcgue, M., \& Iacono, W. G. (2005). Disruptive behavior and school grades: Genetic and environmental relations in 11 year olds. Journal of Educational Psychology, 97(3), 391-405.

Jones, J. D. (2002). Plea for a measure of understanding: The importance of intensive psychotherapy in the treatment of children with ADHD. Psychotherapy: Theory, Research \& Practice, 39, 12-20.

Jung, C. G. (1969). The archetypes and the collective unconscious. Princeton University Press.

Kalff, D. M. (2003). Sandplay: A psychotherapeutic approach to the psyche. California: Temenos Press.

Kim, D., An, Y., \& Koo, S. Y. (2016). A Meta-analysis of single-subject studies on non-pharmacological interventions for school-aged ADHD children, Journal of Emotional $\mathcal{E}$ Behavioral Disorders, 32(1), $1 \sim 23$.

Kim, G. B. (2008). The effect of music therapy apply to ADHD child, Journal of Intellectual Disabilities, 10(4), 145-162.

Kim, S. O. (2006). The case study of ADHD child with the sand play therapy, The Journal of Play Therapy, 10(2), 37-56.

Kingdon, D., Cardoso, C., \& McGrath, J. J. (2016). Research review: executive function deficits in fetal alcohol spectrum disorders and attention-deficit/hyperactivity disorder-a meta analysis, Journal of Child Psychology and Psychiatry, 57(2), 116-131.

Kyung K. Soo \& Seo, Mia. (2018). The effect of client-centered sandplay therapy on the depression, aggression \& ego development state of children in a community child center. 
Journal of Symbols \& Sandplay Therapy, Vol.10 No.1.

Symbols \& Sandplay Therapy, 9(2), 1-22.

Lee, S. Y. \& Kim, S. H. (2017). A Meta-analysis on the effect of group play therapy on children with ADHD, The Journal of Play Therapy, 21(3), 95-111.

Lee. Y. M. (2004). Effects of integrative play therapy on ADHD children, Korean Journal of Play Therapy, 7(1), 41-57.

Lumley, V. A., Mcneil, C. B., Hershcell, A. D., \& Bahl, A. B. (2002). An examination of gender differences among young children with disruptive behavior disorders. Child Study Journal, 32(2), 89-100.

Maniadaki, K., Sonuga-Barke, E., \& Kakouros, E. (2005). Parents' causal attributions about attention deficit hyperactivity disorder: The effect of child and parent sex. Child. Care, Health and Development, 31(3), 331-340.

Mary A., Slama H., Mousty, P., Massat, I., Capiau, T., Drabs, V., \& Peigneux, P. (2016). Executive and attentional contributions to theory of mind deficit in attention deficit/hyperactivity disorder (ADHD), Child Neuropsychology, 22(3), 345-365.

Meppelink R., Bruin, E. \& Bogels M. S. (2016). Meditation or medication? mindfulness training versus medication in the treatment of childhood ADHD: a randomized controlled trial, BioMed Central Limited.

Neumann, E. (1954). The origins and bistory of consciousness. New York: Princeton University Press.

No, S. H. \& Kim, M. K. (2013). The effects of sandplay therapy on anxiety, interpersonal Stress, and salivary cortisol levels of university students with ADHD tendencies, Journal of Symbols \& Sandplay Therapy, 4(1), 9-15.

Rhee, S. (2015). The Analysis on research status for music therapy in Korea related to children with ADHD, The Korean Journal of Arts Education, 13(1), 151-168

Singer, J. (1973). Boundaries of the soul. New York: Anchor Press.

Sirjana, T. \& Jang, M. K. (2016). The hindu gods, snakes, \& fairies images in the sandplay therapy process of the Nepalese earthquake survivors. Symbols \& Sandplay Therapy, 7(2).

Stolberg, B. V. (2017). ADHD medication; history, science, and issues, California: Greenwood.

Yoon, B. S. (2010). The possibility of meditation based intervention on ADHD, Journal of 
Byungho Jung / Beyond Medications: Understanding Executive Function Deficits of Children with ADHD Through Jungian Sandplay Therapy

Emotinal \& Behavioral Disorders, 26(1), 121-143.

Weinrib, E. L. (2004). Images of the self: the sandplay therapy process. California: Temnos Press.

Received : April 15, 2019

Revised : June 16, 2019

Accepted : June 20, 2019 